Evelyn Stelzl*, Harald H. Kessler, Hans G. Mustafa, Maria E. Mustafa, Brigitte I. Santner, Josef Seier, Marco La Torre and Alexander C. Haushofer

\title{
Alternative detection of SARS-CoV-2 RNA by a new assay based on mass spectrometry
}

https://doi.org/10.1515/cclm-2021-0483

Received April 23, 2021; accepted August 2, 2021;

published online August 12, 2021

\section{Abstract}

Objectives: Accurate detection of SARS-CoV-2 RNA is essential to stopping the spread of SARS-CoV-2. The aim of this study was to evaluate the performance of the recently introduced MassARRAY ${ }^{\circledR}$ SARS-CoV-2 Panel and to compare it to the cobas ${ }^{\circledR}$ SARS-CoV-2 Test.

Methods: The MassARRAY ${ }^{\circledR}$ SARS-CoV-2 Panel consists of five assays targeting different sequences of the SARS-CoV-2 genome. Accuracy was determined using national and international proficiency panels including 27 samples. For clinical evaluation, 101 residual clinical samples were analyzed and results compared. Samples had been tested for SARS-CoV-2 RNA with the cobas ${ }^{\circledR}$ SARS-CoV-2 Test.

Results: When accuracy was tested with the MassARRAY ${ }^{\circledR}$ SARS-CoV-2 Panel, 25 of 27 (92.6\%) samples revealed correct results. When clinical samples were analyzed with the MasSARRAY ${ }^{\circledR}$ SARS-CoV-2 Panel and compared to the cobas ${ }^{\circledR}$ SARS-CoV-2 Test, 100 samples showed concordant results. One sample was found to be inconclusive with the MassARRAY ${ }^{\circledR}$ SARS-CoV-2 Panel. When time-to-results were compared, the new assay showed longer total and hands-on times.

Conclusions: The MassARRAY ${ }^{\circledR}$ SARS-CoV-2 Panel showed a good performance and proved to be suitable for use in the

*Corresponding author: Evelyn Stelzl, Research Unit Molecular Diagnostics, Diagnostic and Research Center for Molecular Biomedicine, Medical University of Graz, Neue Stiftingtalstrasse 6, 8010 Graz, Austria, Phone: +43 316385 73719, Fax: +43 316385 79648, E-mail: evelyn.stelzl@medunigraz.at

Harald H. Kessler and Brigitte I. Santner, Research Unit Molecular Diagnostics, Diagnostic and Research Center for Molecular Biomedicine, Medical University of Graz, Graz, Austria Hans G. Mustafa and Maria E. Mustafa, Medilab - MedizinischChemisches Laboratorium Dr. Mustafa, Dr. Richter OG, Salzburg, Austria

Josef Seier, Marco La Torre and Alexander C. Haushofer, Central Laboratory, Klinikum Wels-Grieskirchen GmbH, Wels, Austria routine diagnostic laboratory. Especially during phases of shortage of reagents and/or disposables, the new test system appears as beneficial alternative to standard assays used for detection of SARS-CoV-2 RNA.

Keywords: MassARRAY ${ }^{\circledR}$ SARS-CoV-2 panel; mass spectrometry; PCR; SARS-CoV-2 RNA.

\section{Introduction}

The COVID-19 pandemic causes an extremely high demand for molecular SARS-CoV-2 testing of respiratory samples. Widespread testing shortages due to this enormous global demand for supply of materials have hampered current diagnostic efforts and thus alternative testing formats are desirable.

Application of mass spectrometry (MS) in laboratory medicine has largely replaced traditional methods for pharmacogenomics, drug levels/toxicology, microbiology, and molecular genetics. For detection of pathogens, nucleic acid testing based on real-time PCR has been used as the major technology. Mass spectrometry has been shown to be highly reliable for detection of amplification products and already been established for screening of human seasonal coronaviruses [1-4]. A new panel developed by Agena Bioscience for their MassARRAY ${ }^{\circledR}$ system (Agena Bioscience, San Diego, CA, USA) uses multiplex RT-PCR for five targets within the genome of SARS-CoV-2, three targets within the viral nucleocapsid $(N)$ gene and two within the ORF1 gene.

The aim of this study was to evaluate the MassARRAY ${ }^{\circledR}$ SARS-CoV-2 Panel (Agena Bioscience, San Diego, CA, USA), for use on the MassARRAY ${ }^{\circledR}$ System (Agena Bioscience). For accuracy testing, proficiency panels from OEQUASTA (Austrian Association for Quality Assurance and Standardization of Medical and Diagnostic Tests; https://oequasta.at/de/) and the Quality Control for Molecular Diagnostics (QCMD; https://www.qcmd.org/) were used. Furthermore, the clinical performance was evaluated with routine clinical samples and compared to real-time PCR using the cobas ${ }^{\circledR}$ SARS-CoV-2 Test (Roche Molecular Diagnostics, Pleasanton, CA, USA). 


\section{Materials and methods}

\section{Molecular assays}

The MassARRAY ${ }^{\circledR}$ SARS-CoV-2 Panel (Agena Bioscience), for use on the MassARRAY ${ }^{\circledR}$ System, is a reverse transcription (RT-PCR)/ MALDI-TOF test intended for the qualitative detection of nucleic acid from SARS-CoV-2 in upper respiratory specimens (nasopharyngeal swab, oropharyngeal swab, nasal and mid-turbinate swabs, and nasal and nasopharyngeal aspirate) and bronchoalveolar lavage (BAL). For extraction of nucleic acids, the chemagic Viral DNA/RNA Kit (PerkinElmer chemagen Technologie GmbH, Baesweiler, Germany) for use on the PerkinElmer Chemagic ${ }^{\mathrm{TM}} 360$ instrument (PerkinElmer, Wallac Oy, Mustionkatu, Finnland) based on the chemagen magnetic bead technology is used followed by amplification employing the iPlex ${ }^{\circledR}$ Pro chemistry on the Labcycler Gradient instrument (SensoQuest, Biomedizinische Elektronik, Germany). Thereafter, a sequence-specific primer extension step is performed, in which a single nucleotide is added to the probe, using the Extend primers and iPLEX Pro reagents. After desalting, products are transferred to a SpectroCHIP ${ }^{\circledR}$ Array and then loaded into the MassARRAY ${ }^{\circledR}$ Analyzer according to the manufacturer instructions. Data acquired are processed by MassARRAY ${ }^{\circledR}$ Typer/SpectroAcquire software and a report is generated. According to the manufacturer's package insert, the panel consists of five assays targeting different sequences of the SARS-CoV-2 genome: N1, N2, N3, ORF1/nsp3, ORF1ab/nsp10. The panel also contains an MS2 phage assay that controls for all steps from RNA purification through to results with each patient sample and must be positive for a correct negative result. A SARS-CoV-2 positive result is defined as two or more positive assays. In case of a single positive assay, the result is inconclusive and the whole panel testing should be repeated.

For comparison of routine clinical samples, the in vitro diagnostics/Conformité Européenne-labeled cobas ${ }^{\circledR}$ SARS-CoV-2 Test (Roche) for use on the cobas ${ }^{\circledR} 6800 / 8800$ Systems (Roche Molecular Diagnostics) was used [5]. Selective amplification of target nucleic acid from the sample is achieved by the use of target-specific forward and reverse primers for ORF1a/b nonstructural region that is unique to SARS-CoV-2. In addition, a conserved region in the structural protein envelope $E$ gene is chosen for pan-Sarbecovirus detection. Furthermore, an RNA internal control is introduced into each specimen during sample processing to monitor the entire sample preparation and PCR amplification process.

\section{Study design}

For accuracy testing, samples from national and international proficiency panels were used. The national panels included the First and the Second Austrian national SARS-CoV-2 virus genome detection External Quality Assessment (EQA) scheme distributed by the Austrian Association for Quality Assurance and Standardization of Medical and Diagnostic Tests (OEQUASTA) [6, 7]. The international panels included the QCMD 2020 SARS-CoV-2 EQA program distributions (2020 Pilot study, C1 Challenge, and C2 Challenge) [8].

For evaluation of the clinical performance, 101 anonymized leftover nasopharyngeal or oropharyngeal swab samples collected in $\mathrm{eSwab}^{\mathrm{TM}}$ tubes (Copan, Brescia, Italy) were analyzed and results compared. Samples had been collected at the Medical University of Graz and at medilab, Salzburg, Austria and tested for SARS-CoV-2RNA with the cobas ${ }^{\circledR}$ SARS-CoV-2 Test within $24 \mathrm{~h}$ after collection. Thereafter, samples were immediately frozen at $-80^{\circ} \mathrm{C}$ until analyzed with the MassARRAY ${ }^{\circledR}$ SARS-CoV-2 Panel.

\section{Results}

When the accuracy of the MassARRAY ${ }^{\circledR}$ SARS-CoV-2 Panel was evaluated with national programs, all except of two positive sample could be detected (Table 1). With the international programs, the MassARRAY ${ }^{\circledR}$ SARS-CoV-2 Panel detected all samples positive for SARS-CoV-2 correctly. Negative samples of both programs were found to be negative. Figure 1 shows examples of a positive and a negative result.

Of 101 clinical samples, 71 tested positive with the cobas ${ }^{\circledR}$ SARS-CoV-2 Test and 30 were found to be negative. Ct values of the positive samples ranged from 17.11 to 36.03 for the ORF1a/b target and from 17.64 to 38.03 for the $E$ gene when analyzed with the cobas ${ }^{\circledR}$ SARS-CoV-2 Test. With the MassARRAY ${ }^{\circledR}$ SARS-CoV-2 Panel, 70 (98.6\%) clinical samples tested positive. One cobas $^{\circledR}$-positive sample was found to be inconclusive (only ORF1 detected) with the MassARRAY ${ }^{\circledR}$ SARS-CoV-2 Panel. With the cobas ${ }^{\circledR}$ SARS-CoV-2 Test, this sample showed Ct values of 35.94 $(\mathrm{ORF} 1 \mathrm{a} / \mathrm{b})$ and 36.86 ( $E$ gene). All cobas ${ }^{\circledR}$-negative samples were determined correctly. The control MS2 phage assay indicating valid results was found to be positive for all samples.

The lab flow analysis for 94 samples is shown in Table 2. For the MassARRAY ${ }^{\circledR}$ SARS-CoV-2 Panel, the total time was $540 \mathrm{~min}$ including a hands-on time of $195 \mathrm{~min}$. For the cobas $^{\circledR} 6800 / 8800$ system, the time-to-result was $240 \mathrm{~min}$ including a hands-on time of $60 \mathrm{~min}$.

\section{Discussion}

The MasSARRAY ${ }^{\circledR}$ SARS-CoV-2 Panel is a combined reverse transcription PCR/mass spectrometry assay for qualitative detection of SARS-CoV-2 RNA. In a recent study, Wandernoth et al. reported this assay to be a reliable method for detection of SARS-CoV-2 [9]. However, in that study, only 22 SARS-CoV-2-positive and 22 SARS-CoV-2-negative clinical samples were included. In our study, two national (OEQUASTA) and three international programs (QCMD) were used for accuracy testing and 101 clinical samples for clinical performance. 
Table 1: Accuracy testing utilizing national and international proficiency panels.

\begin{tabular}{|c|c|c|c|c|}
\hline Sample code & Sample content & Matrix & Results expected & Results obtained \\
\hline \multicolumn{5}{|c|}{ First Austrian national SARS-CoV-2 virus genome detection EQA scheme } \\
\hline 01 & SARS-CoV-2 & $\mathrm{SC}$ & pos & pos \\
\hline 02 & SARS-CoV-2 & SC & pos & pos \\
\hline 03 & SARS-CoV-2 & $\mathrm{SC}$ & pos & neg \\
\hline 04 & Coronavirus negative & SC & neg & neg \\
\hline \multicolumn{5}{|c|}{ Second Austrian national SARS-CoV-2 virus genome detection EQA scheme } \\
\hline 01 & SARS-CoV-2 & SC & pos & pos \\
\hline 02 & Coronavirus negative & $\mathrm{SC}$ & neg & neg \\
\hline 03 & SARS-CoV-2 & $\mathrm{SC}$ & pos & pos \\
\hline 04 & Coronavirus negative & $\mathrm{SC}$ & neg & neg \\
\hline 05 & SARS-CoV-2 & $\mathrm{SC}$ & pos & neg \\
\hline \multicolumn{5}{|c|}{ QCMD 2020 pilot study } \\
\hline CVOP20S-01 & SARS-CoV-2 & $\mathrm{TM}$ & pos & pos \\
\hline CVOP20S-02 & Coronavirus NL63 & $\mathrm{TM}$ & neg & neg \\
\hline CVOP20S-03 & SARS-CoV-2 & TM & pos & pos \\
\hline CVOP20S-04 & Coronavirus $\mathrm{OC} 43$ & $\mathrm{TM}$ & neg & neg \\
\hline CVOP20S-05 & Coronavirus negative & $\mathrm{TM}$ & neg & neg \\
\hline CVOP20S-06 & SARS-CoV-2 & TM & pos & pos \\
\hline CVOP20S-07 & SARS-CoV-2 & TM & pos & pos \\
\hline CVOP20S-08 & SARS-CoV-2 & $\mathrm{TM}$ & pos & pos \\
\hline \multicolumn{5}{|c|}{ QCMD 2020 C1 challenge } \\
\hline SCV_101C1-01 & Coronavirus 229E & $\mathrm{TM}$ & neg & neg \\
\hline SCV_101C1-02 & SARS-CoV-2 & $\mathrm{TM}$ & pos & pos \\
\hline SCV_101C1-03 & SARS-CoV-2 & $\mathrm{TM}$ & pos & pos \\
\hline SCV_101C1-04 & SARS-CoV-2 & TM & pos & pos \\
\hline SCV_101C1-05 & SARS-CoV-2 & $\mathrm{TM}$ & pos & pos \\
\hline \multicolumn{5}{|c|}{ QCMD 2020 C2 challenge } \\
\hline SCV2_101C2-01 & Coronavirus $\mathrm{OC} 43$ & $\mathrm{TM}$ & neg & neg \\
\hline SCV2_101C2-02 & SARS-CoV-2 & TM & pos & pos \\
\hline SCV2_101C2-03 & SARS-CoV-2 & $\mathrm{TM}$ & pos & pos \\
\hline SCV2_101C2-04 & SARS-CoV-2 & $\mathrm{TM}$ & pos & pos \\
\hline SCV2_101C2-05 & Coronavirus negative & $\mathrm{TM}$ & neg & neg \\
\hline
\end{tabular}

pos, positive; neg, negative; SC, sodium chloride; TM, transport medium.

The accuracy of the MassARRAY ${ }^{\circledR}$ SARS-CoV-2 Panel was evaluated with two national and three international proficiency panels including 18 positive and nine negative samples for SARS-CoV-2. With the national proficiency panels, both samples containing the lowest concentrations of SARS-CoV-2 RNA were found to be discrepant. The Ct values of these samples had been found to be 38.5 and 35.7 for the $E$ gene when tested by the organizer of the Austrian national SARS-CoV-2 virus genome detection EQA schemes using an in-house assay [6, 7]. These low-positive samples had been missed by 37.3 and $9.9 \%$ of tests used by the participating laboratories. One of the samples (that with the $\mathrm{Ct}$ value of 35.7) was repeat tested with the MassARRAY $^{\circledR}$ SARS-CoV-2 Panel using a double amount of input volume and found to be positive. All negative samples tested negative including those samples positive for seasonal coronaviruses NL63, OC43, and 229E.
When the clinical performance was evaluated, all except of one result obtained by the MassARRAY ${ }^{\circledR}$ SARS-CoV-2 Panel agreed with those obtained with the cobas ${ }^{\circledR}$ SARS-CoV-2 Test. One sample tested inconclusive with the MassARRAY ${ }^{\circledR}$ SARS-CoV-2 Panel and thus should have been repeat tested; however, due to insufficient sample volume, this could not be done. We presume that the result obtained by the cobas ${ }^{\circledR}$ SARS-CoV-2 Test was correct as this fully automated assay has been reported to show an excellent performance $[8,10]$.

Comparison of lab flow analyses revealed both longer total and hands-on times for the MassARRAY ${ }^{\circledR}$ SARS-CoV-2 Panel when testing 94 samples. The new assay allows processing of up to 376 samples within $18 \mathrm{~h}$ (corresponding to approximately 2.5 working days). Within a week, up to approximately 4,000 (using 96-well plates per run) or 

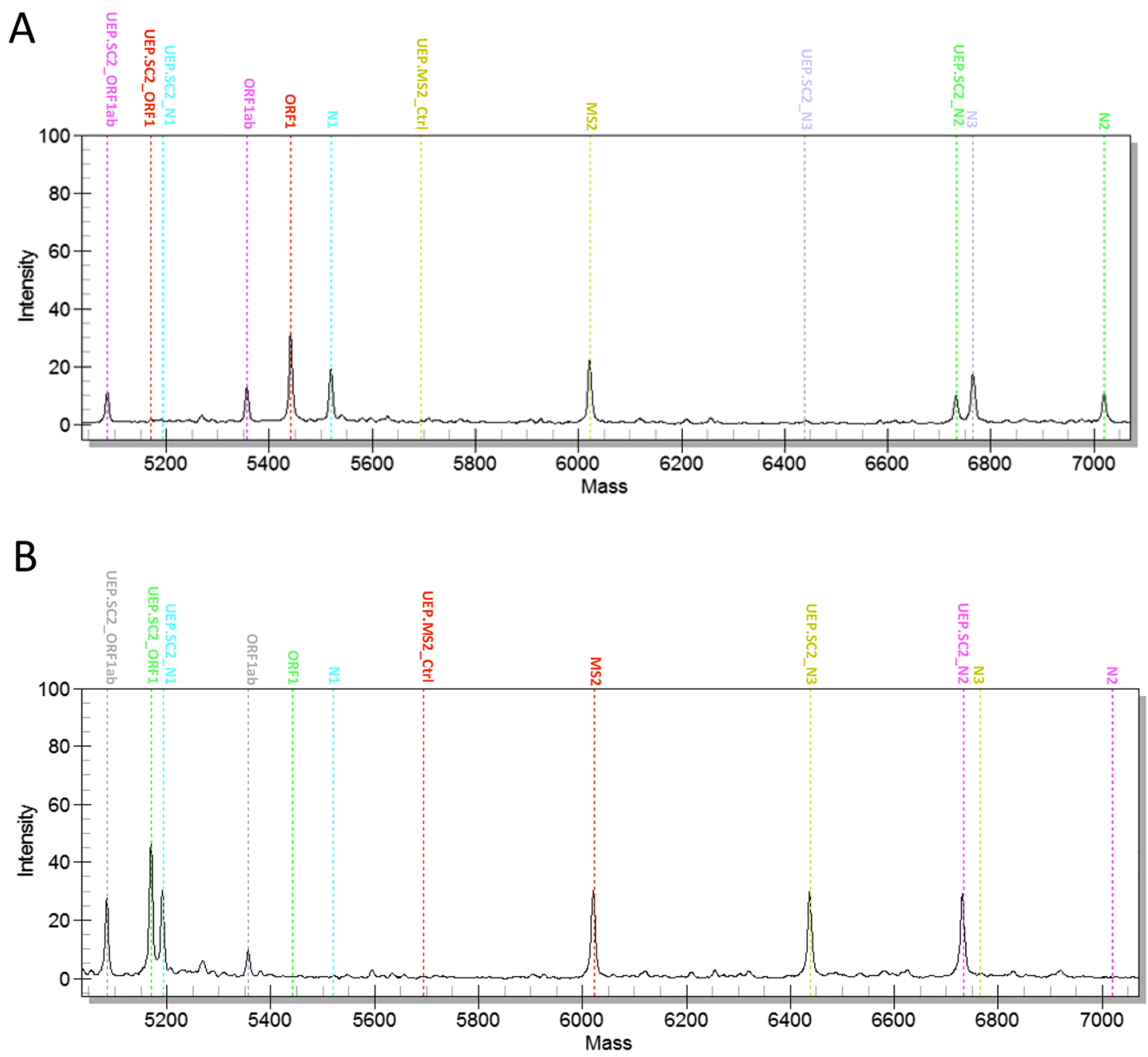

Figure 1: Examples for a positive and a negative result obtained by the MasSARRAY ${ }^{\circledR}$ SARS-CoV-2 panel.

In the sum spectra $(A, B)$, the expected mass peaks for the respective amplification products are highlighted with a dashed line. In the positive example (A), peaks for amplification products of the ORF1ab/nsp10, ORF1/nsp3, N1, N3, and N2 (from left to right) can be identified. In the negative example (B), peaks of unextended primers can be observed. The amplification product of the control MS2 phage assay is seen in both the positive and the negative result.

Table 2: Lab flow analysis for 94 samples analyzed with the cobas ${ }^{\circledR}$ $6800 / 8800$ system or the MassARRAY ${ }^{\circledR}$ SARS-CoV-2 panel.

\begin{tabular}{|c|c|c|c|c|}
\hline \multirow[t]{2}{*}{ Steps } & \multicolumn{2}{|c|}{$\begin{array}{c}\text { Cobas }^{\circledR} \\
\text { SARS-CoV-2 test }\end{array}$} & \multicolumn{2}{|c|}{$\begin{array}{c}\text { MasSARRAY }^{\circledR} \\
\text { SARS-CoV-2 panel }\end{array}$} \\
\hline & $\begin{array}{r}\text { Total } \\
\text { time, } \min \end{array}$ & $\begin{array}{l}\text { Hands-on- } \\
\text { time, } \min \end{array}$ & $\begin{array}{r}\text { Total } \\
\text { time, min }\end{array}$ & $\begin{array}{l}\text { Hands-on- } \\
\text { time, } \min \end{array}$ \\
\hline Pre-analytic & 60 & 60 & 60 & 30 \\
\hline Extraction & 90 & 0 & 120 & 60 \\
\hline qPCR & 90 & 0 & 120 & 15 \\
\hline SAP & 0 & 0 & 25 & 10 \\
\hline Extension-PCR & 0 & 0 & 35 & 15 \\
\hline $\begin{array}{l}\text { MassArray } \\
\text { analysis }\end{array}$ & 0 & 0 & 120 & 5 \\
\hline $\begin{array}{l}\text { Data acquisition } \\
\text { and analysis }\end{array}$ & 0 & 0 & 60 & 60 \\
\hline Total time & 240 & 60 & 540 & 195 \\
\hline
\end{tabular}

6,000 (using 384-well plates per run) results can be produced.

\section{Conclusions}

The new MassARRAY ${ }^{\circledR}$ SARS-CoV-2 Panel showed a good performance. It proved to be suitable for use in the routine diagnostic laboratory. Especially during phases of shortage of reagents and/or disposables, the MassARRAY ${ }^{\circledR}$ SARS-CoV-2 Panel appears as beneficial alternative to standard assays used for detection of SARS-CoV-2 RNA.

Acknowledgments: The authors thank Brigitte Elisabeth Lehner for technical support. 
Research funding: None declared.

Author contributions: All authors have accepted responsibility for the entire content of this manuscript and approved its submission.

Competing interests: Authors state no conflict of interest. Informed consent: Not applicable.

Ethical approval: Not applicable.

\section{References}

1. Xiu L, Zhang C, Wu Z, Peng J. Establishment and application of a universal coronavirus screening method using MALDI-TOF mass spectrometry. Front Microbiol 2017;8:1510.

2. Seger C, Salzmann L. After another decade: LC-MS/MS became routine in clinical diagnostics. Clin Biochem 2020;82:2-11.

3. Fung AWS, Sugumar V, Ren AH, Kulasingam V. Emerging role of clinical mass spectrometry in pathology. J Clin Pathol 2020;73: 61-9.

4. Angeletti S, Ciccozzi M. Matrix-assisted laser desorption ionization time-of-flight mass spectrometry in clinical microbiology: an updating review. Infect Genet Evol 2019;76:104063.
5. Poljak M, Korva M, Knap Gašper N, Fujs Komloš K, Sagadin M, Uršič T, et al. Clinical evaluation of the cobas SARS-CoV-2 test and a diagnostic platform switch during $48 \mathrm{~h}$ in the midst of the COVID-19 pandemic. J Clin Microbiol 2020;58:e00599-20.

6. Görzer I, Buchta C, Chiba P, Benka B, Camp JV, Holzmann H, et al. First results of a national external quality assessment scheme for the detection of SARS-CoV-2 genome sequences. J Clin Virol 2020; 129:104537.

7. Buchta C, Görzer I, Chiba P, Camp JV, Holzmann H, PuchhammerStöckl E, et al. Variability of cycle threshold values in an external quality assessment scheme for detection of the SARS-CoV-2 virus genome by RT-PCR. Clin Chem Lab Med 2020;59:987-94.

8. Matheeussen V, Corman VM, Donoso Mantke O, McCulloch E, Lammens C, Goossens $\mathrm{H}$, et al. International external quality assessment for SARS-CoV-2 molecular detection and survey on clinical laboratory preparedness during the COVID-19 pandemic, April/May 2020. Euro Surveill 2020;25:2001223.

9. Wandernoth P, Kriegsmann K, Groh-Mohanu C, Daeumer M, Gohl P, Harzer $\mathrm{O}$, et al. Detection of severe acute respiratory syndrome coronavirus 2 (SARS-CoV-2) by mass spectrometry. Viruses 2020;12: 849.

10. Fung B, Gopez A, Servellita V, Arevalo S, Ho C, Deucher A, et al. Direct comparison of SARS-CoV-2 analytical limits of detection across seven molecular assays. J Clin Microbiol 2020;58:e01535-20. 